\title{
Dinâmica Temporal do Assentamento e os Projetos de Vida da Juventude Rural ${ }^{1}$
}

\author{
Leandro Gomes Reis Lopes ${ }^{2}$ e Denis Barros de Carvalho ${ }^{3}$
}

Resumo: Esta pesquisa aborda a apropriação do espaço pela juventude rural, tendo em perspectiva a dinâmica temporal de um assentamento rural organizado pelo Movimento dos Trabalhadores Rurais Sem-Terra (MST), em Teresina, Piauí. Os jovens assentados pesquisados foram inseridos na luta pela terra, em sua maioria, em decorrência da decisão de seus pais. Assim, a partir dessa luta eles tiveram que (re)construir seus projetos de vida no espaço do assentamento, num processo tensionado pelas transformações do mundo rural e das problemáticas próprias da juventude do campo. A partir de uma pesquisa participante, por meio da técnica de grupo focal, com o Coletivo de Jovens já existente, foram discutidos os processos e vetores que atuam na construção dos projetos de vida dos jovens rurais com relação ao assentamento Vale da Esperança. As informações, analisadas por meio da técnica de Categorização da Análise de Conteúdo, apontaram para a importância da forma de inserção na terra como também atuação de mediadores sociais na apropriação do espaço e construção de projetos de vidas voltados para o próprio assentamento.

Palavras-chaves: Apropriação do espaço; Juventude rural; Identidade.

Abstract: In this research the appropriation of space by rural youth is discussed, taking in perspective the temporal dimension of sustainability of a rural settlement organized by Landless Rural Workers Movement (MST), in Teresina, Piaui, Brasil. Mostly young settled people are inserted in the struggle for land as a result of the decision of their parents. Therefore, from this fight they will have to (re) construct their life projects within the settlement, tensioned by transformations of the rural world and characteristic problems of the youth in rural areas. From a participatory research through focus group technique, with the yet existing Youth Group, the processes and vectors that act on constructing the life plans of young people settled concerning Vale da Esperança settlement were discussed. The data were analyzed using the technique of Categorization of Content Analysis, which

1. Data de submissão: 2 de abril de 2015. Data de aceite: 2 de setembro de 2015 .

2. Universidade Federal do Piauí. Teresina, Piauí, Brasil. E-mail: leandrogrlopes@gmail.com

3. Universidade Federal do Piauí. Teresina, Piauí, Brasil. E-mail: denispsi@bol.com.br 
pointed to the importance of the form of insertion of the classes on land as well as activities of the social mediators in the space appropriation and construction of life projects for the settlement itself.

Key-words: Space appropriation; Rural youth; Identity.

DOI - http://dx.doi.org/10.1590/1234-56781806-9479005304001

Classificação JEL: Z13.

\section{Introdução}

A questão da sustentabilidade socioambiental é complexa na medida em que envolve a articulação das dimensões ambiental, política e cultural entre si (ENNES, 2010). Seu quadro natural influencia as diferenças entre assentamentos, podendo impedir, inclusive, o seu desenvolvimento produtivo, dependendo de suas propriedades ecossistêmicas. Neste contexto, a diversidade cultural da população dentro dos assentamentos, com diferentes experiências de enfrentamentos históricos e projetos de vida, interfere nas atividades socioeconômicas e os efeitos no ambiente constituem outro aspecto importante. Existe também a dimensão política que aponta para a organização e participação nos processos de planejamento e gestão ambiental, como também na articulação com outros grupos e instituições (ALBUQUERQUE, 2002; ALBUQUERQUE, COELHO e VASCONCELOS, 2004). Além destas características, o empreendimento rural, tal como os projetos de assentamentos, deve ser também sustentável ao longo do tempo, incluindo, assim, aspectos da sucessão familiar.

A dimensão temporal da sustentabilidade de um assentamento rural está relacionada com a sua continuidade ao longo de várias gerações e com a reprodução social do homem do campo, numa perspectiva mais ampla. A permanência da juventude rural no campo, neste contexto, tem importante papel, pois é considerada uma espécie de elo entre o passado e o futuro do assentamento. No entanto, de acordo com Silvestro et al. (2001), vem crescendo o número de estabelecimentos com casais adultos sem a presença permanente de jovens devido à migração para as cidades, independente da densidade dos conhecimentos tácitos elaborados a partir de suas vivências no campo. Este processo tem sido preocupação de movimentos sociais, políticas públicas e de pesquisas acadêmicas. Ao fazer um levantamento bibliográfico da produção sobre juventude rural no início deste século, Castro et al. (2009) constataram certa associação entre os jovens rurais com a questão da migração ou invisibilidade, percebidos muitas vezes como desinteressados e distanciados do mundo rural.

O papel social e o lugar que a juventude ocupa dentro das relações sociais têm colocado os jovens rurais num duplo movimento. De um lado, eles são atraídos pelo estilo de vida urbano e a possibilidade de maior acesso à saúde, educação e emprego como também na busca de reconhecimento, afastando-se da reprodução social da família pautada na autoridade paterna, vigilância e controle com efeito no desinteresse pelo meio rural. De outro, a juventude articula lutas pela permanência na terra enquanto atores sociais na construção de sua identidade a partir 
de seu lugar de pertença sendo sujeito de demandas próprias, embora nem sempre reconhecidas nas políticas públicas (CASTRO, 2009).

A juventude assentada por meio de Projetos de Reforma Agrária, por seu turno, apresenta certas particularidades, quando confrontada com outras formas de vivenciar a juventude rural em outros contextos. A entrada na luta pela terra representa um movimento e histórias de enfraquecimento de vínculos, quando não de rupturas. Isso, no entanto, não quer dizer que esse processo ocorra de maneira homogênea, pois é atravessado por diversas dimensões, que, inclusive, vão além de aspectos meramente econômicos, como, por exemplo, a questão de gênero.

Assim, em muitos casos, esses jovens se inserem na luta pela terra por meio da decisão familiar, com o objetivo de melhoria da qualidade de vida, tendo que mudar de residência e escola, como também se afastar de uma rede familiar e comunitária, e a partir deste marco, construírem novos projetos de vida em outro espaço. Assim, o estabelecimento rural que foi desapropriado será o substrato para a construção de novas subjetividades por meio de apropriação desse espaço.

A vida no assentamento, ao mesmo tempo em que aponta para a construção de outras possibilidades e identidades apresenta obstáculos, os quais dificultam a própria permanência dos jovens no campo. Se por um lado, apesar de todas as dificuldades enfrentadas pelos jovens assentados, o meio rural se apresenta, atualmente, como uma alternativa viável para o projeto de vida, por outro lado, existem os desafios de concretização dos projetos de Reforma Agrária numa perspectiva que contempla várias gerações, num mesmo espaço, sem que isto represente um processo constante de luta pela terra. Além disso, existem outros fatores que atuam na conformação dos projetos da juventude voltados para o próprio assentamento. Entre eles podem ser citadas as transformações do rural e seu estreitamento com o urbano, assim como as políticas públicas descontextualizadas, que não atendem às demandas da juventude enquanto categoria social, e a questão da sucessão hereditária. Estas dimensões influenciam nos projetos de vida da juventude assentada. Por fim, existe a questão relacionada com a apropriação dos jovens ao seu espaço no assentamento, e mais particularmente, com suas atividades, sentimentos, representações. Assim, ao atuarem na construção de suas identidades relacionadas à terra, ou mais precisamente, enquanto assentados, tornam-se elementos importantes na construção dos projetos de vida. $\mathrm{O}$ fato de não se vincularem à terra, inclusive, pode prejudicar a sustentabilidade do Projeto de Reforma Agrária, numa perspectiva intergeracional.

Assim, tendo em consideração que não se deve impor a permanência da juventude rural no campo a todo custo com o objetivo de equalizar o problema da agricultura camponesa, é importante discutir que fatores atravessam este processo. Dessa forma, neste estudo se discutirá a (re)construção de projetos de vida dos jovens rurais, a partir de um estudo de caso de um projeto de assentamento organizado pelo Movimento dos Trabalhadores Rurais Sem-Terra, Vale da Esperança, localizado próximo à cidade de Teresina (PI).

\section{Problematizando a juventude rural}

A juventude é uma categoria social e historicamente construída em que as características variam de acordo com o contexto em que se encontram inseridas, de forma que na compreensão dos jovens rurais se deve levar em conta as transformações que ocorrem na sociedade rural, tais como a diversificação das atividades produtivas, para além da agrícola; maior integração do rural com o urbano; transformações dos estilos de vida e valores; melhoria da mobilidade geográfica e descentralização política administrativa. Para Jurado e Tobasura (2012), tais transformações têm levado os jovens, de maneira geral, a migrarem com o objetivo de melhorar suas condições de vida, tendo como principal destino as cidades, uma vez que eles enfrentam problemas de exclusão social mais intensos que os adultos. 
Como no meio rural existe a dificuldade de acessos aos direitos sociais e ao trabalho desejado que possibilitam o bem-estar que eles almejam, é comum os jovens rurais acreditarem ter mais oportunidade de educação e trabalho nas cidades. Além disso, a hierarquia do urbano sobre o rural, em que o rural é tido como lugar em que se vive e mora mal, pode ser considerada como mais um fator que mobilize os jovens a migrarem do campo. No entanto, as observações da pesquisa de Castro (2009) apontam que existe um número considerável de jovens que deseja permanecer no assentamento.

Neste sentido, Castro (2005) ressalta a existência do paradoxo "ficar" e "sair", pois da mesma forma que jovens podem ficar para desfrutar as coisas boas do campo (qualidade de vida, relação familiar e comunitária), eles podem sair, visando melhores condições de trabalho e estudos. Assim, é construída uma ambiguidade na percepção dos adultos sobre os jovens rurais. Quando o termo juventude é utilizado de maneira genérica, espontaneamente surge a vinculação com o desinteresse ou recusa do trabalho na roça. De um lado, quando existe uma relação de proximidade com os jovens rurais, eles passam a ser percebidos como jovens que buscam um futuro melhor por meio da educação e do trabalho urbano. Também, a partir de um olhar sociológico, pode-se afirmar que existe uma controvérsia relacionada à migração dos jovens, pois se é considerada como um problema para a reprodução social do campo e da produção familiar em particular, com outra perspectiva a migração da juventude rural é considerada como uma estratégia de manutenção do próprio lote e reprodução da família camponesa. Considerando a dificuldade de obtenção de renda da terra para a manutenção da família, os jovens muitas vezes procuram emprego formal nas proximidades do assentamento, como forma de aquisição de recursos mensais, que os tornem independentes das intempéries do meio agrícola ou da negociação de preços com atravessadores, os quais, via de regra, compram seus produtos por valor abaixo do mercado. Essa migração dos jovens, portanto, pode ser compreendida como importante para a reprodução social da família, diminuindo a pressão por terras (CASTRO et al., 2009; CORDEIRO, 2009).

Embora nos discursos oficiais seja destacada a preocupação com a continuidade do assentamento ou movimentos sociais, a juventude não percebe este reconhecimento social concreto. Oliveira Junior e Prado (2013) destacam três fatores que contribuem para a invisibilidade dos jovens rurais. $\mathrm{O}$ primeiro está relacionado com o fato de os jovens rurais casarem e trabalharem cedo, aspecto que os descaracterizam como jovens. O segundo fator é a subordinação geracional em que eles se encontram, dificultando o seu aparecimento como atores políticos. Por fim, são relevantes as diferentes formas de socialização e os aspectos econômicos.

No que diz respeito a fatores que promovem a saída dos jovens do campo, Castro $(2005,2009)$ ressalta a autoridade e controle paterno, pois a busca de autonomia será realizada, em sua maioria, pela saída de casa. Em muitos casos, representa apenas um afastamento dessas relações de controle e não uma ruptura com a família ou vínculos com a terra. Em sua pesquisa antropológica, essa autora destacou que os jovens rurais são expostos à autoridade paterna e subordinação nas relações sociais. Além disso, eles são considerados de pouca confiabilidade, devido ao suposto desinteresse pelo campo e atração pela cidade, com repercussão na construção de sua identidade social, inclusive.

As relações de hierarquias e autoridade dos adultos em relação aos jovens, por sua vez, são reproduzidas nas políticas públicas, as quais têm como interlocutor o chefe da família, tanto no sistema de assistência técnica como no acesso aos créditos. Sales (2006) afirma que os jovens são excluídos dos projetos dos órgãos públicos da assistência ao assentamento, pois:

"embora todos os membros da família sejam denominados de assentados [sujeito que obtém a concessão de terra], juridicamente o assentado é apenas aquele cadastrado pelo Incra, e na quase totalidade são homens adultos, considerados pela instituição como o chefe da família" (p. 90). 
Aliás, as políticas públicas são criticadas por não levarem em consideração os aspectos intergeracionais do assentamento, ou seja, a reprodução da unidade de produção ao longo do tempo. Prejudica-se, assim, a sustentabilidade econômica e social desses projetos, pois a divisão do lote para os filhos pode torná-la inviável do ponto de vista da reprodução social dos assentados. Assim, o dilema dos jovens é ampliado pelo fato de a área cultivada não comportar todos os filhos, sendo, portanto, necessária a saída de alguns para a cidade ou para a continuação da luta por terras. A constituição de novas famílias dentro do assentamento tem como limite o próprio espaço físico, tornando a terra insuficiente para a reprodução social da família ampliada, a partir de certo limite (CASTRO et al., 2009; SALES, 2006).

Não havendo espaço para a permanência das novas famílias oriundas dos filhos dos assentados, muitas vezes essas novas famílias têm que migrar para a cidade ou então ingressarem novamente na luta pela terra, caso queiram permanecer na terra. Cordeiro (2009), conclui que:

"Portanto, a terra concedida pela política
pública da reforma agrária apresenta diferen-
tes significados em torno da sua apropriação.
Para a primeira geração, ou seja, para os titu-
lares da terra, esta é vista como uma conquista
da família em relação à situação de "morada"
que viviam anteriormente, sendo um espaço
de residência e ao mesmo tempo de produção.
No entanto, para os jovens assentados, com
exceção do sucessor (a segunda ou mesmo ter-
ceira geração), a terra é considerada primor-
dialmente um espaço de residência, uma vez
que não é suficiente em extensão para morar e
trabalhar ao mesmo tempo. No entanto, para
ambas as gerações, a terra é considerada um
bem que deve ser administrado em conjunto"
(p. 561 ).

Dessa forma, é importante esclarecer a diferença entre sucessão e herança. Enquanto a sucessão está relacionada à reprodução social da unidade familiar, a herança representa a distribuição dos bens familiares se estendendo a todos os filhos. A articulação da sucessão no lote com outros interesses é tida pelos pais como uma espécie de ruptura com um projeto que valoriza a terra como conquista e meio de vida. Os jovens assentados, por sua vez, se identificam com a terra mais pela simbologia da conquista da terra do que na figura do profissional agropecuário (CASTRO, 2005). Logo, a lógica de ambos varia de acordo com cada contexto, articulando questões de ordem moral, gênero, aposentadoria, escolarização e educação tácita voltadas para atividades rurais, num processo decidido pelo pai, via de regra (SILVESTRO et al., 2001; CORDEIRO, 2009; BRUMER, 2005).

Um estudo de caso realizado por Brumer (2005) aponta como este processo pode repercutir na construção de projetos da juventude rural. É mostrado que o jovem pode ser obrigado a permanecer na terra, por assim dizer, não devido a um interesse pessoal, mas pela implicação de ordem moral, como o cuidador de um pai idoso. Na questão da sucessão hereditária, os que ficam com essa função acabam recebendo o lote como compensação, ou então, "assumem seu destino" de forma resignada, percebido como um caminho sem volta, diante da dificuldade de estudo e emprego na cidade, de forma que o campo aparece como oportunidade de sobrevivência.

Contudo, de uma maneira geral, a juventude assentada tem a pretensão de assumir o lote, devido à valorização da conquista da terra, como também em decorrência da luta e esforços desprendidos, independentemente de uma precedente história de vida no meio rural. A identidade dos jovens assentados com a terra está mais relacionada com sua conquista e como espaço produtivo do que como patrimônio material em si. Assim, a forma de inserção na terra conforma sua identidade para com ela, e direciona projetos de vida no meio rural (CASTRO, 2005). É neste sentido, que o MST incentiva a criação de agroindústrias como estratégia para favorecer o aumento da renda dos assentados por meio do beneficiamento de produtos agrícolas e a permanência dos jovens nos projetos de assentamentos.

Ferreira e Bonfim (2013) ressaltam alguns fatores que favorecem a permanência da juventude rural no campo. Primeiramente, estas 
autoras ressaltam a interiorização das instituições de ensino superior como fator que favorece a permanência do jovem no campo. No caso especifico do semiárido, pontuam a necessidade de uma educação contextualizada, para contribuir com a ampliação do conhecimento do próprio local, reconhecendo as suas potencialidades. Nesse sentido, ressaltam, ainda, que é importante a elaboração de políticas públicas a partir da participação popular, em que os jovens reivindiquem políticas e projetos a partir de suas próprias demandas.

Os jovens mesclam em seus sonhos sua cultura de origem com a urbana, numa experimentação de sentimentos opostos. Embora busquem ascensão social por meio da educação e trabalho para além de atividades de roça, eles desejam muitas vezes continuar no campo. Também, em muitas situações, os projetos não são individuais, representando sonhos coletivos e de preocupação com o assentamento, uma vez que estes projetos podem ser referência para a família, comunidade e sociabilidade (SALES, 2006). Por outro lado, aqueles jovens que não desejam permanecer no lote e buscam na universidade outros projetos de vida, tendem a ingressar em áreas relacionadas às ciências agrárias.

Por fim, Furlani e Bonfim (2013) destacam que a participação dos jovens em grupos igualitários amplia seu autoconhecimento, bem-estar, liberdade, assim como seu sentimento de pertencimento. A rede de apoio social pode proteger os jovens diante das situações de vulnerabilidade. Dessa forma, acreditam, ainda, que as políticas públicas devam fortalecer a rede de proteção dos jovens rurais diante das diversas vulnerabilidades sociais, com o objetivo de possibilitar a criação de projetos de vida mais estruturados e críticos.

\section{Metodologia}

\subsection{Caracterização da área de estudo}

A pesquisa de campo foi desenvolvida no Projeto de Assentamento Vale da Esperança, localizado na zona rural do município de Teresina (PI), distante $27 \mathrm{~km}$ do centro da cidade. Da área total da antiga fazenda, de 1.162,469 ha, foram desapropriados 884,66 ha, tendo capacidade para assentar 64 famílias, abrangendo 169 pessoas atualmente. A população do assentamento é predominantemente composta por pessoas jovens, uma vez que $51,5 \%$ têm até 29 anos.

O processo de construção do assentamento Vale da Esperança iniciou-se em 2002, com a articulação e mobilização em bairros periféricos da cidade de Teresina com reuniões semanais, encabeçadas pelo Movimento dos Trabalhadores Rurais Sem-Terra (MST). A maioria dos assentados vivia em favelas, vilas e/ou em condições precárias. Embora, no geral, sejam pessoas que tiveram alguma relação com o campo, tanto de forma direta quanto indireta, isto não se constituiu necessariamente em pré-condição. São encontradas pessoas com o modo de vida tipicamente urbano, entretanto, devido ao contexto social e econômico, elas encaram os assentamentos de reforma agrária, como uma possibilidade de melhoria em suas vidas.

A primeira ocupação ocorreu ainda em 2002, no Cocal, com 25 famílias. No dia 17 de janeiro de 2003 foi realizada a segunda ocupação na Fazenda Funil (próximo ao atual assentamento), com 150 famílias inicialmente, sendo a primeira de todo o Governo Lula e de grande significado para o grupo. Com a divulgação da notícia, mais pessoas foram se incorporando ao movimento, ao ponto de terem por volta de $750 \mathrm{em} 2003$, período que simbolizou o auge do assentamento. Dessa mobilização, surgiram cinco assentamentos localizados próximos entre si.

O decreto de desapropriação da fazenda ocorreu em fevereiro de 2005, sendo ocupada em setembro do mesmo ano. No entanto, a imissão de posse aconteceu somente em 2006. Na ocasião 92 famílias estavam acampadas. Foi somente em janeiro de 2007 que as famílias assentadas se transferiram para o local, em que a Agrovila se encontra instalada. Assim, da primeira ocupação à implantação do assentamento pelo Instituto Nacional de Colonização e Reforma Agrária, houve duração de aproximadamente, quatro anos. Atualmente, o assentamento encontra-se 
em fase de consolidação, já tendo conseguido diversos investimentos via prefeitura do município, por meio do Orçamento Popular, como a Casa de Beneficiamento Agrícola e um Campo Agrícola Irrigado.

O sistema produtivo é predominantemente de agricultura de subsistência, sendo poucos produtos destinados para a comercialização. Dada a diversidade de potencial e aptidão dos assentados, existem várias linhas de produção, destacando-se a avicultura, cultivo de sequeiro e de hortaliças. Grande parte da produção é realizada nos quintais das casas dos próprios assentados, delimitadas no espaço da Agrovila, cujo centro abriga uma horta comunitária. A maior extensão do terreno do assentamento é, ainda, dividida em igual parte para os assentados desenvolverem suas atividades de forma individual, de modo que atualmente são utilizados, aproximadamente, 22,8 ha para cultivo de roça, sendo em sua maioria no toco (milho, arroz, feijão, abóbora, mandioca e macaxeira) em consórcio, sendo essas culturas utilizadas para a subsistência da família e o excedente, comercializado. Para a pastagem cultivada, a área é de 26,103 ha.

\subsection{Métodos e técnicas}

A pesquisa foi delineada a partir do modelo qualitativo, por se constituir o mais adequado, devido à complexidade e natureza desse estudo. $\mathrm{O}$ primeiro passo dessa empreitada foi a familiarização com o contexto em questão, em que o pesquisador, por meio de visitas e reuniões sistemáticas, buscou conhecer a comunidade e que a comunidade o conhecesse, para que houvesse sensibilização de ambas as partes para a realização da proposta. Também, informações foram buscadas junto ao Incra e em outros documentos secundários, tais como as notícias encontradas na internet. Em sequência, o pesquisador percorreu todo o território ligado ao assentamento, anotando as diversas impressões a partir de observação livre, enquanto estratégia ainda da familiarização.

Para a compreensão da dimensão temporal do assentamento foi utilizada a estratégia de coleta de dados por meio dos grupos focais com os jovens do Vale da Esperança. As entrevistas foram realizadas juntamente com o Coletivo de Jovens, que já existia e atuava, de forma que o grupo não foi criado exclusivamente com essa finalidade. Aliás, a própria mobilização para efetivação dos encontros foi realizada pelos próprios jovens. Todas as reuniões foram gravadas e transcritas, a partir das quais foi realizada análise de conteúdo após leitura exaustiva do material.

Antes de começar cada entrevista era realizada uma apresentação dos participantes, da pesquisa e seus procedimentos. No momento em que foi abordada a questão da confidencialidade dos dados foi colocada a possibilidade aos jovens da escolha de pseudônimo, garantindo o anonimato das falas. No entanto, eles foram unânimes em afirmar que poderia colocar seus próprios nomes no momento da escrita da dissertação ou de qualquer outro material acadêmico. Assim, ao invés de preservar a identidade dos informantes, optou-se por respeitar a opinião e autonomia do grupo pesquisado.

O grupo focal foi realizado em três encontros realizados nos finais de semana, tendo o primeiro deles como temática principal o cotidiano da juventude assentada, buscando captar as ações cotidianas desenvolvidas no lugar. O segundo teve como tema norteador a identidade e o protagonismo juvenil, focalizando as atividades orientadas para o lugar. A última discussão teve como tema os projetos de vida dos jovens, apontando para os seus projetos de futuro. Tal divisão estava baseada na dimensão da ação-transformação do conceito de apropriação do espaço de Pol e Vidal (2005).

A média de presença dos jovens nos grupos foi de 11 pessoas, com média de idade de 16,11 e desvio padrão de $\pm 4,73$ anos, tendo rotatividade entre elas nas reuniões. Como o Coletivo de Jovens ampliou a faixa etária para 12 anos, a maioria deles tinha entre 12 e 14 anos. Estes, por sua vez, eram denominados pelo próprio grupo como sendo os "jovens mais jovens". Os outros eram simplesmente jovens. Não havia os "jovens mais velhos". No entanto, observou-se que, de uma maneira geral, a fala se concentrava nas 
pessoas com mais experiência no MST e assentamento, com discursos mais densos e elaborados ao invés de falas curtas e pontuais, tal como apresentada pelos mais novos.

Todas as informações colhidas foram gravadas e transcritas, de acordo com técnicas específicas, procurando durante todo momento, manter sua fidedignidade. Com o objetivo de manter a coerência entre os pressupostos teóricos e metodológicos e o modo mais adequado para analisar os conteúdos encontrados nas entrevistas, foi elaborado um plano geral de análise e tratamento dos dados. Desta forma, para analisar as informações obtidas, foi utilizada a Técnica de Análise de Conteúdo Temática (BARDIN, 1991).

Por fim, após uma análise sistemática e criteriosa das informações, foi realizada uma discussão sistemática avaliadora, como parte obrigatória de qualquer trabalho de cunho comunitário. Foram apresentados os resultados da investigação, de maneira participativa, para compartilhar com as pessoas participantes ou interessadas o que foi produzido. Dessa maneira, foi possível conhecer o sentido dado coletivamente pela avaliação, tanto pelas pessoas que participaram quanto as que não colaboraram. Assim, pode-se verificar se as informações produzidas refletiam o sentimento do público pesquisado (MONTERO, 2006).

\section{Resultados e discussão}

\subsection{Um novo espaço: inserção na luta pela terra}

A apropriação do espaço de assentamento por pessoas que lutaram por um pedaço de terra, tendo como perspectiva a reprodução social do campesinato ou de (re)construção de projetos de vida, é um processo complexo e multifacetado, que se inicia antes mesmo da imissão de posse decretada pelo Estado. A compreensão deste processo exige um olhar sobre o que significa o campesinato ou os trabalhadores rurais, pois, para a maioria dos assentados, a história de vida está centrada no campo.

Os jovens entrevistados, em geral, eram crianças quando vieram para o acampamento, em decorrência de uma decisão de seus pais. A entrada na luta pela terra foi concretizada por meio da inserção na história sociofamiliar, com objetivos de outras oportunidades de vida construídas a partir da terra. Os jovens tiveram que acreditar que aquilo era o melhor para eles. Todos ressaltaram que foi uma mudança bem radical, pois se tratava de uma ruptura de vínculos, nos quais já estavam familiarizados. Havia diversas relações já estabelecidas, seja, com outras famílias, amigos, vizinhança, escola, entre outras. De uma hora para outra passaram a viver em um local sem nenhuma estrutura.

As condições de vida no acampamento apresentam algumas dificuldades, que são sentidas com maior intensidade, levando-se em consideração o modo de vida anterior. A água, que antes chegava às casas pela rede oficial de abastecimento, no acampamento, passou, na maioria dos casos, a ser buscada em baldes retirados de poço cacimbão. A energia elétrica não existia. As casas eram coletivas e sem estrutura, não havendo, por exemplo, espaço para um quarto individualizado ou sendo vulneráveis às intempéries climáticas. Além disso, existia a insegurança de serem despejados a qualquer momento, havendo sempre uma pessoa na função de vigia.

Ferreira e Bonfim (2013) destacam o sofrimento gerado pelo desenraizamento, falta de apropriação espacial e perda dos parâmetros identitários da comunidade, a que o sujeito pertencia em decorrência do processo de migração. São estabelecidas rupturas afetivas com as pessoas, objetos e lugares, de forma que o sentimento de pertencimento pode prejudicar a adaptação na nova localidade e gerar sentimento de insegurança e de desestabilização. Estas autoras, ao estudarem a afetividade e as influências para a imigração de jovens que haviam terminado o ensino médio e estavam próximos de sair para outro lugar, destacam como relevante a insegurança que os jovens passam diante da cidade nova, como também o afastamento com os laços familiares e sociais da sua origem, visto que eles encontram proteção nestes vínculos.

Para os jovens, restavam-lhe acreditar no que seus pais verbalizavam, ressaltando a esperança de 
que um dia conseguiriam aquilo pelo qual estavam lutando. E dessa maneira, os jovens se percebem também como lutadores, fazendo parte dessa história. Foram ressaltadas, também, as dificuldades pelas quais passaram ou passariam se continuassem a viver nas áreas periféricas em que moravam. Nesse contexto, visualizavam que o assentamento representava um campo de oportunidade, no qual dificilmente teriam na parte urbana do município. Assim, eles acreditavam na possibilidade de terem uma vida digna e se desenvolverem no próprio campo, sem estar na "cidade".

Neste sentido, Barbanti (2006) afirma que a mobilização de retorno à terra não é impulsionada somente por fatores de ordem econômica ou de sobrevivência, mas também pelas lembranças e memórias de suas vidas, num movimento de volta às origens e de autonomia no processo produtivo, que nesse caso, está ancorado em seus pais. Aliás, as dificuldades iniciais do assentamento são sustentadas diante do desejo de viver na terra. Segundo a autora,

"para os que lutam pela terra, o assentamento significa uma interrupção da história de migração e falta de raízes. Significa também sanar a precariedade desse tipo de vida, seja no campo, como assalariados temporários ou permanentes, seja na periferia das cidades" (BARBANTI, 2006, p. 56).

No entanto, essa transição pode ser sentida inicialmente, também de maneira negativa, como falta de opção, e não como possibilidade de construção de projetos de vida no vínculo com a terra. Houve caso em que a jovem foi para a terra quando já havia o assentamento, tendo resistido o quanto pôde para ficar no contexto em que morava. Merece destaque um trecho da entrevista que ressalta esses dois pontos de vista encontrados no assentamento:

Ana Cleide - Acho que sou estranha (em tom irônico), mas eu a partir do momento que fui pro acampamento, que eu vi a minha mãe lutando, meu vô, todo mundo. Todos lutando. Eu botei o pé naquele lugar e eu gostei. E aí, eu acho que eu pensei, a minha vida vai ser aqui, eu vou vir por isso, eu vou lutar com a minha mãe e vai ser isso. E até hoje eu não me arrependo. [...] Sofri mesmo. Peguei muita água, sofri. Arre Maria, eu sofri muito e nunca tive vontade de ir embora. Nunca. Muito pelo contrário. Cada obstáculo que tinha me dava mais vontade de ficar e lutar por melhoras, que hoje isso aqui pra nós é um sonho, é uma vitória (26 anos).

Leandro - você tinha levantado a mão?

Fran - não, é porque eu só discordei, porque eu nunca tive esse pensamento, não [...]. Eu morava no assentamento, mais não tinha a vontade de permanecer no assentamento. $\mathrm{Na}$ verdade, eu vim mais morar assim, porque não tinha aonde ficar em Teresina, né. Por falta de opção eu vim morar no assentamento. E a partir da convivência como os familiares e amizades, que a gente vai criando, né, no decorrer do tempo, aí a gente vai criando e vai mudando assim, a forma de pensar em relação ao local que você vive, mais é assim (26 anos).

Um mesmo acontecimento pode ser percebido de maneiras diferenciadas pelas pessoas que participaram desse processo. Neste caso, a inserção na terra pode ser vivenciada como esperança de um porvir melhor, como também falta de opção. Independentemente de como tenha ocorrido, a família foi um fator importante nesse processo, seja pela decisão em si, ou pelo menos enquanto influência. Assim, cabe destacar o papel desempenhado pela família ou das pessoas com quem convive no acampamento nesse processo de transição e construção dos novos vínculos. A trajetória de vida dos jovens ou até mesmo das crianças deve estar inserida num horizonte maior, conectando a história de vida no contexto urbano com a atual, para dar-lhe um sentido de continuidade, apesar da ruptura. Com efeito, reforça-se a identidade de que eles também são lutadores da Reforma Agrária, relatada pela mesma vivência de sofrimento.

Apesar das dificuldades, o acampamento é experiência que traz bastante recordações e, segundo relatos, em alguns pontos é melhor do 
que o próprio assentamento. Os jovens destacaram que a estrutura organizacional e a participação das pessoas nas atividades do cotidiano e as vivências comunitárias vão se perdendo aos poucos a partir do momento da imissão da posse da terra. Nesse contexto, foram destacados como exemplos representativos do período de acampamento as oficinas de caráter produtivo ou mesmo de conscientização política por meio das lideranças do assentamento ou de militantes do MST, que se deslocavam para fornecer apoio e ajudar na organização do acampamento. Essas vivências se tornaram importantes na vida deles no assentamento. Assim, a apropriação do espaço fica diferenciada, dentre vários outros fatores, a partir das experiências vivenciadas no acampamento. Os jovens que o vivenciaram e que têm fortes memórias dessa época, por exemplo, têm consciência política mais forte. $\mathrm{O}$ acampamento, dessa forma, foi decisivo na formação das identidades e projetos de vida dos sujeitos, pois os que vivenciaram constroem perspectivas diferentes em relação àqueles que não vivenciaram ou ainda eram crianças.

\subsection{Cotidiano da juventude no assentamento}

As atividades de ação-transformação realizadas pelos sujeitos, de acordo com Pol e Vidal (2005), atuam na apropriação do espaço, e consequentemente na formação de vínculos $\mathrm{e}$ identidades para o lugar. $\mathrm{O}$ enraizamento no assentamento, considerado como espaço de produção e moradia, é um indicador da permanência da juventude no lugar em que vive.

Neste sentido, Fischer (1994) pontua que, quando não se sente integrado, o indivíduo não busca familiaridade, ou seja, ocorre a não pertença. O sentimento de pertencimento a uma comunidade desenvolve o sentimento de satisfação ao lugar, não sendo, portanto, uma relação direta entre características do espaço e relações sociais. O tempo é um fator importante, pois os usos, os significados e os afetos estão relacionados com o tempo de ocupação. Outro fator importante é a estrutura social, que é revelada de alguma forma no sistema espacial.
Já dentro do assentamento, são realizadas algumas atividades que atuam na construção do vínculo com a terra. Entre as interações cotidianas realizadas no lugar destacam-se, como rotina, a mescla de atividades produtivas com estudos e lazer, não se diferenciando dos demais estudos sobre a juventude rural. Eles costumam cuidar das atividades produtivas dentro da unidade de produção doméstica pela manhã, como a criação de animais, cultivo da horta e de tarefas domésticas. Nesta última, por sua vez, não é realizada nenhuma distinção de gênero de forma que tanto os homens quanto as mulheres realizam as mesmas atividades.

Uma das demandas do grupo no que diz respeito às atividades de rotina está relacionada com a dimensão do lazer. Foi comum, mostrarem as dificuldades de momentos e de espaços de lazer e de diversão, reclamando que não tinham "nada a fazer". A partir daí são pensadas e criadas várias estratégias, em diversos níveis de articulação. Foi relatado o cinema, em que eles se organizavam e os jovens iam assistir filmes na casa de um deles, com comidas e bebidas, como também atividades esportivas e recreativas no campo. Ainda algumas atividades são realizadas fora do próprio assentamento, como passeios em clubes.

Além destas ações, destacam-se três tipos de atividades orientadas para o lugar como, por exemplo, as reunióes periódicas do Coletivo de Jovens, participação em eventos ou mobilização do MST, como também a participação em cursos de extensão ou capacitação. Por fim, a juventude é responsável pela organização de festas ou comemoração de datas especiais. No entanto, com relação a este aspecto, a juventude, ao mesmo tempo que é reconhecida como categoria social, por outro lado se sente limitada na organização dos eventos, devido ao fato de as decisões ficarem subordinadas à Coordenação Geral do Assentamento. Assim, no geral, enquanto os jovens organizam eventos, a Coordenação do Assentamento articula políticas públicas consideradas pelos próprios jovens como mais necessárias.

Todas as atividades realizadas pela juventude, sejam elas no seu cotidiano ou voltadas 
para o lugar, são importantes para a construção dos projetos de vida, uma vez que ocorrem a partir de suas vivências no espaço em que moram. Por mais que os jovens apontem para um futuro promissor, este futuro é moldado a partir de suas condições reais e concretas de existência.

\subsection{Construção dos projetos de vida a partir do assentamento}

Os projetos de vida, para Furlani e Bonfim (2013), são eixos organizadores que orientam o sujeito para o futuro, antecipando-o a partir do aqui-agora. São definidos os objetivos para aspectos significativos para a vida do sujeito, levando em consideração a sua própria história. Tais projetos pessoais são construídos sob um fundo sócio-histórico e pela interação com outros indivíduos, abrindo campos de possibilidades. Assim, existem dois movimentos dialéticos em constante interação. De um lado, os contextos de vida influenciam os projetos de vida e vice-versa. Do outro lado, as pessoas influenciam os projetos que irão influenciar as próprias pessoas.

O projeto de vida, para Gonçalves et al. (2008), está relacionado com o equilíbrio entre o real e o ideal, podendo ser transformador tanto no plano das ideias como também na realidade concreta. Nesse processo, o sujeito articula sua biografia individual com os valores do grupo que pertence, por meio das trocas sociais. Para os autores, a juventude tem como eixo central para a construção de seus projetos a estabilidade econômica e afetiva.

$\mathrm{Na}$ construção de projetos de vida pela juventude assentada, os jovens pesquisados por Firmiano (2009) afirmam que, neste espaço, sua perspectiva de futuro ocorre diferentemente do que aconteceria na cidade, pois estavam desassistidos e desamparados pelo Estado e pela comunidade. $\mathrm{O}$ assentamento possibilita condições materiais e espirituais, que dão garantia e segurança aos jovens para projetar, e sempre na perspectiva do assentamento. $\mathrm{O}$ modo de vida assentado para eles acaba sendo seu projeto de vida, devido à qualidade de vida e às relações sociais de produção, que são diferentes da cidade. Até mesmo os jovens militantes que têm os projetos de vida voltados para o movimento mantêm seu assentamento como um ponto sólido de referência. Entre uma mobilização e outra, eles voltam para o assentamento de origem.

$\mathrm{Na}$ abordagem dos projetos de futuros dos jovens assentados pesquisados, foram consideradas as expectativas para o futuro, ressaltando-se os fatores que interferem, como incentivo à sua permanência, como também as dificuldades encontradas por eles na concretização desses projetos, levando os jovens não somente a abandonar seus sonhos, mas a enfraquecer os vínculos com o espaço do assentamento Vale da Esperança. A maioria deles pontuou como projeto de futuro o desejo de permanecer no próprio assentamento em que mora, uma vez que o meio rural proporciona um modo de vida contrastante com a vida nos centros urbanos, sendo comum a comparação entre ambos. Destacaram, por exemplo, a tranquilidade da vida rural, em oposição aos constantes ruídos na cidade, além da vulnerabilidade em decorrência da questão habitacional. Relataram também a segurança, liberdade e a sociabilidade entre as pessoas, especialmente com os vizinhos, pois mesmo morando próximo a um centro urbano eles ainda mantêm a tradição da solidariedade comunitária, por exemplo. Tal proximidade, aliás, possibilita o acesso aos meios tecnológicos, como a internet, celular, computador, entre outros. Pontuaram, por fim, a possibilidade de trabalhar no quintal de sua casa própria com a perspectiva do autossustento, produzindo alimentos saudáveis, posto que o plantio ocorre sem agrotóxicos. Dois relatos ilustram os aspectos levantados por eles, como importantes na produção do desejo de permanência dos jovens no meio rural:

Ana Cleide - eu desejo ficar aqui até... porque a gente na cidade, não, não, eu acho que... sei lá. Acho que devido eu ter vindo há muito tempo de lá e todo dia ver no noticiário, é muita coisa que acontece, é muita violência, é muito, não sei... Eu acredito que seja por isso que eu queira ficar aqui. Aqui é bom, aqui todo 
mundo se conhece. Aqui todo mundo ajuda a todo mundo. Não quer dizer que na cidade não aconteça, porque existem lugares, lá, né, que quando a gente precisa, tem uns que ajudam, mais aqui é... é tudo, é o paraíso.

Karla - é o que é seu. Se você for morar fora e você não tem dinheiro pra comprar uma casa, vai morar alugada, pagar água, pagar energia, pagar tudo. Cadê a calma?

Trabalhar a agricultura familiar como a gente trabalha. É tão bom você poder acordar, é, falar com o seu vizinho, conversar, trocar experiências, trabalhar no seu próprio quintal, ter a sua horta. O seu alimento ser produzido por você mesmo, você se autossustentar em questão de produção, e ainda mais você sabendo que tá produzindo um produto de qualidade, que você faz o máximo possível orgânico, pra chegar mais perto possível de um produto orgânico (Alana, 19 anos).

Barbanti (2006) destaca que a relação dos assentados com seu lugar é da ordem do estético também, uma vez que apreciam aquela paisagem, seus cheiros, sons, enfim, por meio de todos os sentidos. Essa disposição integrada de experiências passadas atua como referências das percepções e ações. A natureza é uma ideia construída socialmente, de forma que os sentimentos, valores e atitudes para com ela serão os mais diversos, variando de acordo com a história pessoal, o lugar em que vive ou viveu e a visão de mundo, temores, aspirações, ambições e necessidade etc. Assim, embora não haja uma distinção nítida entre campo e cidade nos aspectos geográficos e socioeconômicos, existem no imaginário das pessoas visões socialmente construídas.

$\mathrm{O}$ relato de uma jovem aponta para o seu desejo de permanecer na terra. Afirma que, mesmo tendo a possibilidade de morar em outro lugar, uma vez que já trabalha e teria condições para tanto, prefere ficar no próprio assentamento, pela consideração da história de luta que tiveram que travar para estar lá. Pois, segundo ela:

o fato maior, é realmente tudo que a gente passou, né, toda a nossa luta, todas as dificuldades que a gente teve pra conseguir ganhar, ter o que a gente tem hoje, faz com que a gente realmente não queira sair daqui, porque foi tudo muito sofrido pra uma pessoa, pra uma criança, tipo a gente que entrou como criança e tá passando por tudo que a gente passou, vai gerando na nossa cabeça, realmente, a vontade de dar valor a tudo que a gente, realmente, deu trabalho, que a gente teve que ajudar também, pra gente poder ter (Alana, 19 anos).

No tocante à relação da juventude com o assentamento, pode-se dizer que, para os jovens, a terra significa a possibilidade de construção de projetos de vida com maior autonomia e dignidade, afastando-se do caminho de muitos jovens, que vivem nas periferias das cidades, com o trabalho informal ou ilícito. Eles fazem um contraponto com a vida urbana, ressaltando a segurança, a falta de barulho, oportunidade de falar e ser escutado além da relação afetiva para com o grupo, com o movimento social, a luta, de forma que valorizam todo o esforço empreendido para conseguir chegar onde estão. Para Firmiano (2009):

No limite, para esses jovens, a terra sintetiza em significado o encontro com a dignidade que a sociedade brasileira lhes negou ao longo de toda a sua história; o encontro com valores, referências e sentimentos que até então, em sua maior parte, não integravam seu repertório cotidiano nas relações que estabeleciam. Por essa razão, superam os constrangimentos de viver debaixo da lona preta. Pois, na terra, as necessidades e as dificuldades que experimentam têm causa: é a vida (p. 224-225).

Os pais, por seu turno, incentivam também a permanência dos jovens no meio rural com o entendimento de que no campo terão melhores oportunidades, como por exemplo, a aprendizagem proporcionada pelas vivências rurais, ou direito à terra, tirando daí a sobrevivência. Os pais acreditam, de acordo com o relato dos jovens, que fora do assentamento as dificuldades são maiores, principalmente no que diz respeito à moradia, trabalho e renda, sem levar em conta o desemprego e violência na cidade. 
No entanto, a construção dos projetos de futuro da juventude pesquisada não ocorreu de forma homogênea para todos, apesar de aparentemente apontarem para a mesma trajetória. A vivência no acampamento é crucial ao ponto de se afirmar a existência de dois grupos dentro do Coletivo. Aqueles jovens que o vivenciaram com maior intensidade, trazendo memórias vivas daquele tempo, tiverem forte influência do MST tanto na vinculação com a terra como também na elaboração de seus projetos de vida. Os "jovens mais jovens" por sua vez, tiveram influência maior da educação do campo.

Quando perguntados aos “jovens mais jovens" sobre seus projetos de futuros, eles não responderam inicialmente, ficando breve tempo em silêncio, talvez por motivos de acanhamento, uma vontade contrária à da maioria do grupo, ou por ainda não se preocuparem com esta questão devido à própria idade. Os "jovens mais velhos", falando sobre eles, acreditavam que eles teriam possivelmente a vontade de morar na cidade,

que é justamente aquilo que a gente sempre fala nas outras reuniões, dialogando com eles. Que os jovens, que já vêm de assim diante, que eram mais velhos, têm aquele pensamento de ficar aqui. Mas aqueles mais novos, acho que devido não ter aquele incentivo, não têm aquele pensamento de querer ficar aqui. São poucos, pouquíssimos que tem (Karla, 18 anos).

No entanto, quando a pergunta foi feita de forma mais concreta, pedindo para que se imaginassem daqui a 20 anos, uma única pessoa tida como sendo dos "jovens mais jovens" respondeu, manifestando o seu desejo de viver longe do assentamento, embora tenha como objetivo de vida ser técnica em zootecnia. No diálogo ficou claro que seu desejo era de fuga de uma situação de conflitos familiares e não propriamente do modo de vida rural, num desejo pela cidade. Em nenhum momento alguém afirmou a intenção de ter um projeto de vida tipicamente urbano. Todos eles, se não estavam voltados diretamente para o assentamento, estavam vinculados de alguma forma com o meio rural.
Aqui é interessante destacar a influência de um importante mediador social na construção dos projetos de vida dos "jovens mais jovens". A maioria deles estuda em Escolas Famílias Agrícolas (EFA), que têm como base a Pedagogia da Alternância. Assim, a rotina deles é dividida em dois momentos: parte no assentamento e outra na escola. No entanto, parece não haver uma divisão dicotômica entre estes dois espaços-tempo diferenciados, pois a própria metodologia escolar procura articular a vida acadêmica com a vida no assentamento. Uma das ferramentas de ensino é o Plano de Estudo, que serve para conhecer melhor a própria realidade em que vivem e repassar tais informações ao professor e colegas de sala de aula, possibilitando a troca de conhecimentos entre os estudantes. Além disso, são incentivados a aplicar aquilo que eles aprenderam nas atividades cotidianas do assentamento.

Dessa forma, a interação constante entre escola e comunidade é importante na apropriação do espaço pelos jovens, pois atuam na construção das identidades vinculadas com a terra, seja de camponês, pequeno agricultor, agricultor familiar etc. Além disso, possibilita uma outra relação com o espaço, pois se antes o assentamento era apenas um local de moradia, passam, então, a se implicar cada vez mais, participando de seu cotidiano. Tal aspecto foi ressaltado por uma jovem, que disse:

A gente veio passar a entender quando a gente foi estudar a partir deste ano nas escolas EFA Baixão, que é o Baixão do Carlo, que a gente veio entendendo mais sobre o campo agrícola, que aqui a gente tava só morando mesmo não participava, aí lá na escola a gente começou a aprender as coisas da zootecnia, os coisas de como se tratar dos animais a parte que o professor (nome do professor) ensinava, né.., é veterinárias, essas coisas. Aí veio passar a servir para gente aqui dentro do assentamento. Ajudou muito isso aí (Saionara,15 anos).

Assim, as EFAs não promovem uma ruptura entre os dois espaços em que os estudantes convivem: assentamento e escola. Pelo contrário, elas estreitam os vínculos entre ambos, além de 
atuarem na produção da identidade do jovem rural. Aqui se pode afirmar que a identidade é construída em dois âmbitos, articulados entre si. Se por um lado, sua filosofia pedagógica está voltada para a formação do trabalho com a terra, numa identidade do homem do campo como um ser genérico, sua metodologia educativa, ao trazer para a escola a realidade dos próprios estudantes, promove os vínculos deles com o lugar em que moram. No caso em questão do objeto de estudo, as EFAs atuam na construção da identidade dos jovens rurais de um assentamento específico, ou seja, uma identidade singular.

Já para os jovens que vivenciaram a experiência do acampamento têm seus projetos de futuro, de alguma maneira, reforçados pela postura do MST. Este movimento social salienta, de um lado, a importância de formação de novos militantes, futuros quadros dirigentes, para a reprodução da luta e construção de um projeto popular-democrático para o Brasil. De outro lado, eles reforçam a permanência nos assentamentos na construção cotidiana do projeto político do movimento na fração conquistada no território (FIRMIANO, 2009).

Os jovens pesquisados afirmaram que, no tempo de acampamento, havia as oficinas ou formações políticas realizadas pelos militantes do MST, nas quais era discutida a importância de não deixar "a cultura de luta" adormecer. Os jovens que vivenciaram a experiência do acampamento e participaram do trabalho de base trazem na memória a história do Movimento, como também conhecem seus hinos, místicas e música.

Barbanti (2006), neste sentido, afirma que a memória é ponto importante na construção do sentimento de identificação e pertença com o grupo social, de modo que ela nunca é individual. Tal sentimento produz inserção no grupo social que compartilha de memórias relacionadas à vivência na terra, fortalecendo a luta, seja para ocupação ou para a construção do lugar. O próprio movimento de luta pela terra tem seu discurso legitimado no apelo ao passado, seja do ponto de vista religioso em que Deus deu a terra para todos, ou na recuperação histórica da formação dos grandes latifundiários. Neste processo, as lembranças de injustiça vêm à tona até serem canalizadas nos movimentos sociais, como estratégia para reverter a situação.

A dissolução dessa referência para o grupo pode ter efeito na sua própria desmobilização política enquanto grupo, principalmente para os "jovens mais jovens". Existe uma bidirecionalidade da interação pessoa e seu ambiente, compreendida a partir de sua complexidade, pois o fato dos jovens estarem ali aponta para a história do grupo. Assim, como forma de estimular a participação, especialmente dos "jovens mais jovens" no Coletivo de jovens que estava se enfraquecendo, eles estão organizando um projeto para resgatar toda essa cultura em parceria com um militante do MST. Pretendem estudar as cartilhas, conhecer o MST e a questão agrária, como também aspectos importantes da cultura popular e da camponesa. O próprio assentamento é organizado pelo MST, do qual eles fazem parte e foram responsáveis pela organização política.

\subsection{Dificuldades de realização dos projetos de vida}

As necessidades de reprodução social da família camponesa vão conformando projetos de vida. Assim, devido às dificuldades de os jovens se inserirem nas atividades produtivas com incentivo do Estado, procuram oportunidade fora do assentamento. Foi relatado que os jovens pensam em ajudar os pais a sustentar a família e, quando não encontram trabalho e renda no contexto em que vivem, vão trabalhar em outras cidades ou até mesmo em outros estados. Existem casos de pessoas profissionalmente bem qualificadas que, ao encontrarem alternativas de trabalho em outros lugares, passaram a mandar dinheiro para os seus familiares.

O caso de dois jovens irmãos, que estão inseridos no contexto da reprodução social da família e das fragilidades das políticas públicas voltadas para o campo, é bem ilustrativo na análise do desejo de permanência no meio rural, pois adotaram estratégias diferentes, embora um deles tenha o assentamento como sua residência, traba- 
lha na cidade como professora da Escola Família Agrícola, lecionando inclusive para alguns dos jovens que participam do coletivo. Passa os dias letivos na escola e finais de semana no assentamento. Seu irmão trabalha numa empresa privada tipicamente urbana, com o sentimento de estar trabalhando em algo que era contra, por entender que está dando lucro para outras pessoas. Seu relato deixa claro os empecilhos impostos pelas políticas públicas voltadas para a juventude rural, como a burocracia e a dificuldade de iniciar um projeto produtivo, fato evidenciado em sua fala:

\begin{abstract}
Aí, eu vou, não! Vou atrás, num programa que eu vou esperar um ano pra mim receber? Vou investir, não sei se vou ganhar. Aí, o jovem vai o que, vai arriscar? Vai ter essa visão de empreendedor aos 19 anos? Não vai, ele vai ver a primeira visão, tu vai trabalhar lá, tu vai ganhar um salário. Tu vai, tu vai. O cara vai mesmo, depois está arrependido, aí, assim o cara vê que a única, a melhor coisa, a melhor coisa que poderia ter acontecido era aquilo. Trabalho fora, mais realmente, não é. A melhor coisa que poderia ter acontecido é eu ter colocado o meu projeto lá, ter sido aprovado, e eu ter investido aqui dentro (Ulisses, 21 anos).
\end{abstract}

Os cursos e projetos agrícolas destinados ao assentamento apresentam certa peculiaridade, pois não são destinados diretamente para os jovens, são voltados para as famílias, dentro do entendimento de agricultura familiar. Assim, será enquanto filhos de assentados que eles se inserem nesses projetos, caso seja possível participar, pois alguns exigem a idade mínima de 18 anos. Foi pontuado durante a discussão que eles precisam lutar, por assim dizer, pelo seu reconhecimento, pois as vagas dos cursos são limitadas. Por isso, têm que mostrar disposição e capacidade para ocuparem tais vagas.

Essas políticas públicas foram consideradas precárias, de forma que eles acabam se inserindo indiretamente, uma vez que as políticas vêm direcionadas para a família como um todo. Ainda neste aspecto, ressaltam as dificuldades impostas pela burocracia, seja pela questão da idade ou pela operacionalidade, como é o caso do acesso à Declaração de Aptidão ao Pronaf (DAP), uma vez que ela é restrita aos assentados, ou seja, os donos dos lotes, tendo respaldo jurídico. O jovem não obtém a sua própria DAP, de forma que qualquer investimento dependerá da cota e limite do seu pai. Dessa forma, pode-se afirmar que esses percalços atuam como empecilho à permanência dos jovens no meio rural.

A juventude, aliás, critica a lógica do governo, pois para ela não faz sentido a exigência de ter que ser dono de um lote, ocupar vaga de uma família que também está precisando, enquanto eles poderiam produzir no próprio lote, morando na casa de seus pais, caso a burocracia permitisse. Para os jovens, a DAP deveria ser um bom incentivo para a permanência no campo, dada a possibilidade de trabalho e renda.

Durante o grupo focal foi abordado que até existem políticas públicas voltadas para a juventude rural, embora não tenham sido relatadas quais se destinaram especificamente para o grupo. No entanto, foi ressaltado que "falta coragem de ir atrás" e de buscar concretizar aquilo que é de direito. Começa a se discutir no coletivo de jovens que eles têm o direito de se beneficiar com a riqueza social que é produzida por eles também, para que demandem políticas públicas específicas para a juventude rural.

A questão da sucessão hereditária foi um ponto interessante, pois não se configurava ainda como um problema para os jovens, tendo em vista que aqueles que formam famílias vão morar nas casas desocupadas, pois existe uma espécie de acordo entre os assentados para que as vagas que forem surgindo nos lotes, que por um motivo ou outro ficarem vazias, sejam destinadas aos filhos de assentados, que constituem uma nova família. Outro aspecto ligado à sucessão hereditária diz respeito à percepção de que existem muitas terras, de forma que o assentamento, nestes casos, é compreendido como sinônimo de moradia, favorecida, talvez, pela proximidade da metrópole ou então de que exista muita terra disponível para a reprodução social de várias famílias. 
Quando questionados sobre a possibilidade de entrar novamente na luta pela terra, em decorrência dos limites físicos impostos pelo próprio assentamento para comportar a criação das famílias dos filhos dos assentados, a maioria não estava disposta. Somente um ressaltou que entraria, motivado pela possibilidade do DAP. O restante trouxe recordações do sofrimento que passara e eles não estariam dispostos a passar por isso novamente. Além disso, se questionaram que já lutaram e conseguiram a terra, para depois ter que lutar e mudar novamente? Assim, buscam outras estratégias que assegurem o aspecto intergeracional, sem precisar que a reforma agrária seja uma permanente desapropriação de terras.

Quando perguntados sobre a perspectiva de vida em longo prazo, eles se imaginam morando e contribuindo no assentamento, com os quintais produtivos, de forma que o assentamento se tornaria modelo. Quando instigados sobre as dificuldades do DAP, eles foram bastante otimistas quanto às mudanças nas políticas públicas voltadas para a permanência dos jovens no campo. Pontuaram a proposta de fazer um assentamento dentro do assentamento, como uma estratégia de superar as dificuldades impostas pelas políticas.

Outra possibilidade foi a criação de uma cooperativa de beneficiamento de produtos agrícolas e de comercialização, como estratégia de geração de emprego e renda para o assentamento como um todo e especialmente para a juventude rural. Malagodi e Marques (2007) pontuam a importância da elaboração de projetos coletivos de geração de renda como estratégia de inserção social e econômica da juventude e permanência no campo. Um dos jovens pesquisados, aliás, foi enfático afirmando que se os jovens tivessem a possibilidade de plantar no próprio quintal, beneficiando o alimento e garantindo renda, eles não teriam a pretensão de saírem do assentamento, tendo como consequência a fixação do homem do campo na terra, e particularmente da juventude.

A vontade de permanência da juventude no próprio assentamento em que mora está permeada de um sentimento de otimismo muito grande. Os jovens pensam que as dificuldades existentes, ainda latentes para a maioria, serão superadas em curto tempo, pois acreditam na viabilização de políticas públicas voltadas para os filhos de assentados, apesar de terem criticado sua formulação e viabilização concreta e atual. Este otimismo, por sua vez, pode estar relacionado ao forte vínculo com seus familiares e, por isso, há o desejo de manter-se no próprio assentamento, como também uma recusa de travar uma nova luta pela terra, tal como fizerem quando ainda eram crianças ou adolescentes.

\section{Conclusão}

O estudo realizado com o Coletivo de Jovens do assentamento Vale da Esperança levanta pontos importantes para uma reflexão metodológica dentro do campo das pesquisas qualitativas. $\mathrm{O}$ primeiro diz respeito à técnica de grupo focal, a qual serviu não somente para que eles ficassem mais à vontade durante a entrevista, mas também possibilitou a discussão e reflexão pelos participantes, sendo possível aprofundar pontos que dificilmente ocorreria em entrevistas individuais, tendo em vista seu caráter dinâmico e coletivo.

Além disso, é interessante ressaltar o posicionamento colocado pelos jovens quando questionados sobre a confidencialidade dos dados, uma vez que eles fizeram questão de afirmar seus nomes quando da possível publicação de suas falas. Dessa forma, a questão do anonimato não se colocou como um impositivo ético nas pesquisas da área de ciência humanas e sociais, pois os sujeitos pesquisados poderão reivindicar, por assim dizer, o direito de serem ouvidos enquanto sujeitos concretos e não reproduzir certa invisibilidade, vivenciada por eles em outros momentos de sua vida.

Já no que diz respeito aos dados pesquisados, pode-se dizer que a compreensão da dinâmica temporal do assentamento estudado aponta para a importância dos mediadores sociais na construção dos projetos de vida da juventude assentada como também da forma de inserção na terra e do próprio trabalho realizado dentro 
do assentamento. As atividades desenvolvidas e orientadas para o próprio assentamento vão fortalecendo a relação do assentado com o espaço em que vive. Apesar de viverem na zona rural de uma cidade grande, a juventude rural possui uma forte ligação com o campo, sendo um vetor importante na construção de suas identidades e ancoradouro para perspectivas de futuro.

Os dados encontrados apontaram que os mediadores sociais podem ter impactos diferenciados na vida do sujeito, variando de acordo com o ciclo de vida, inclusive. Para os jovens que vivenciaram o acampamento de forma mais intensa, seus projetos de vida voltados para o assentamento remetem à história de luta para estarem onde se encontram agora, sendo importante a atuação do MST. Por outro lado, para os “jovens mais jovens" as Escolas Famílias Agrícolas exerceram influência maior pois, por meio delas, foi sendo criada uma identidade para com a terra, de forma que se estivessem matriculados numa escola tipicamente urbana, a vinculação seria mais fraca, senão nula. Assim, uma educação contextualizada pode ser uma estratégia interessante diante do dilema "ficar" ou "sair", podendo constituir-se em temática para a realização de novas pesquisas.

Apesar das dificuldades, a juventude rural do assentamento Vale da Esperança manifesta claramente o desejo de permanecer de alguma forma vinculada ao espaço em que mora. A construção dos projetos de vida está voltada para o próprio assentamento, indicando que o campo se apresenta como uma alternativa mais viável, devido às oportunidades que os jovens conseguem visualizar. Cabe ressaltar aqui os vários problemas das cidades que repercutem na reprodução de suas existências. Caso existissem melhores condições e principalmente incentivo governamental, os jovens estariam implementando atividades produtivas dentro do próprio assentamento, ajudando no seu desenvolvimento e na reprodução social da família. Assim, faz-se necessário que as políticas públicas consigam captar as particularidades e demandas atuais da juventude rural, sob pena de não alcançar sua eficácia e efetividade.
Neste sentido, é importante aprofundar estudos que busquem compreender a juventude rural levando em consideração as dificuldades e potencialidades vivenciadas pelos jovens no seu cotidiano no assentamento, tendo em perspectiva seu enraizamento na terra em que vivem. A dimensão psicossocial poderá lançar outros olhares sobre a discussão ao abordar temas como identidade, vínculos e afetividade para com a terra do assentamento, na medida em que são importantes fatores para a (re)construção dos projetos de vida da juventude rural voltados para o próprio espaço em que vivem. Apesar dos entraves para a permanência no assentamento apontados por eles, a forte identificação com a história social do grupo e do local em que vivem orientam seu desejo para o próprio meio rural e o assentamento em particular. Se eles trabalham na cidade, trata-se mais de uma necessidade pensada como momentânea, sem perda dos vínculos ou referenciais construídos.

\section{Referências}

ALBUQUERQUE, F. J. B. de. Psicologia Social e formas de vida rural no Brasil. Psicologia: Teoria e Pesquisa, v. 18, n. 1, p. 37-42, 2002.

., COELHO, J. A. P. de. M. e VASCONCELOS, T. C. As políticas públicas e os projetos de assentamento. Estudos de Psicologia, Natal, v. 9, n. 1, p. 81-88, 2004.

BARBANTI, S. Retorno à terra: como elo afetivo e meio de sobrevivência nos assentamentos rurais. São Paulo: Musa Editora/FAPESP, 2006.

BARDIN, L. Análise de conteúdo. Lisboa: Edições 70, 1991.

BRUMER, A. As dimensões gênero e idade em assentamentos de Reforma Agrária. In: FERRANTE, V. L. S. B. e ALY JUNIOR, O. (Orgs.). Assentamentos rurais: impasses e dilemas (uma trajetória de 20 anos). São Paulo: INCRA, ABRA, UNIARA, 2005. p. 351-371.

CASTRO, E. G. et al. Os jovens estão indo embora? A juventude rural e a construção de um ator político. Rio de Janeiro: Mauad X. Seropédica: EDUR, 2009.

CASTRO, E. G. de. Juventude Rural no Brasil: processos de exclusão e a construção de um ator político. Revista 
Latinoamericana de Ciencias Sociales, Niñez y Juventud, v. 7, p. 179-208, 2009.

. O paradoxo "ficar" e "sair": caminhos para o debate sobre Juventude rural. In: FERRANTE, V. LS. B. e ALY JUNIOR, O. (Orgs.). Assentamentos rurais: impasses e dilemas (uma trajetória de 20 anos). São Paulo: INCRA, ABRA, UNIARA, 2005. p. 321-349.

CORDEIRO, M. S. S. Jovens na reforma agrária: perspectiva intergeracional e lógicas de sucessão no assentamento Novo Horizonte/ Campos dos Goytacazes - RJ. Revista IDeAS, v. 3, n. especial, p. 544563, 2009.

ENNES, M. A. Identidade, natureza e sustentabilidade. In: SANTOS, A. C. dos. Filosofia e natureza: debates, embates \& conexões. São Cristóvão: EDUFS, 2010. p. 184- 200.

FERREIRA, K. P. M. e BONFIM, Z. A. C. Juventude no semiárido nordestino: caminhos e descaminhos da emigração. In: LEITE, J. F. e DIMENSTEIN, M. (Orgs.). Psicologia e contextos rurais. Natal: EDUFRN, 2013. p. 89-116.

FIRMIANO, F. D. A formação cultural dos jovens do MST: a experiência do assentamento Mário Lago, em Ribeirão Preto (SP). São Paulo: Editora UNESP; São Paulo: Cultura Acadêmica, 2009.

FISCHER, G. N. Psicologia social do ambiente. Lisboa: Instituto Piaget, 1994. (Perspectivas Ecológicas)

FURLANI, D. D. e BONFIM, Z. A. C. Jovens de ambiente rural e urbano e sua relação com projetos de vida. In: LEITE, J. F. e DIMENSTEIN, M. (Orgs.). Psicologia $e$ contextos rurais. Natal: EDUFRN, 2013. p. 117-143.
GONÇALVES, H. S. et al. Problemas da juventude e seus enfrentamentos: um estudo de representações sociais. Psicologia E Sociedade, v. 20, n. 2, p. 217-225, 2008.

JURADO, C. e TOBASURA, I. Dilema de la juventud en territorios rurales de Colombia: ¿campo o ciudad? Revista Latinoamericana de Ciencias Sociales, Niñez y Juventud, v. 10, n. 1, p. 63-77, 2012.

MALAGODI, E. A. e MARQUES, F. R. de S. Para além de ficar ou sair: as estratégias de reprodução dos jovens em assentamentos rurais. In: CARNEIRO, M. J. e CASTRO, E. G. de (Orgs.). Juventude Rural em Perspectiva. Rio de Janeiro: MAUAD-X, 2007, p. 102-120.

MONTERO, M. Hacer para transformar: el método en la psicología comunitaria. 1. ed. Buenos Aires: Paidós, 2006.

OLIVEIRA JR., O. de e PRADO, M. A. M. A categoria juventude em contextos rurais: o dilema da migração. In: LEITE, J. F. e DIMENSTEIN, M. (Orgs.). Psicologia e contextos rurais. Natal: EDUFRN, 2013. p. 57-88.

POL, E. e VIDAL, T. La apropiación del espacio: una propuesta teórica para compreender la vinculación entre las personas y los lugares. Anuario de Psicología, Barcelona, v. 36, n. 3. p. 281-297, 2005

SALES, C. de M. V. Criações coletivas da juventude no campo político: um olhar sobre os assentamentos rurais do MST. 2006. 296 p. Tese (Doutorado em educação). Universidade Federal do Ceará, Fortaleza, 2006.

SILVESTRO, M. L. et al. Os impasses sociais da sucessão hereditária na agricultura familiar. Florianópolis: Epagri; Brasília: Nead / Ministério do Desenvolvimento Agrário, 2001. 